\title{
A coupled thermal-mechanical numerical model of underground coal gasification (UCG) including spontaneous coal combustion and its effects
}

\author{
Ekneligoda, T.C., ${ }^{*}$ Marshall A.M. ${ }^{2}$ \\ ${ }^{1}$ School of Civil and Environmental Engineering, University of Witwatersrand, Johannesburg, South Africa \\ ${ }^{2}$ Nottingham Centre for Geomechanics, University of Nottingham, Nottingham, UK \\ *Thushan.ekneligoda@wits.ac.za
}

\begin{abstract}
Underground coal gasification (UCG) is a promising option for extracting energy from coal in unworked or hard to access areas of the subsurface. From a geotechnical perspective, UCG involves various complex phenomena resulting from the elevated temperatures induced within the rock surrounding the UCG burn. This paper presents a coupled thermal-mechanical numerical model developed to represent a UCG trial in Wieczorek, Poland. Temperature dependent mechanical properties were assigned according to results obtained from laboratory experiments and data available in the literature. The coal burning process was simulated by modifying the energy balance equation with an additional term related to the calorific value of coal as a source. This source term was described using a time decay function to reflect the fact that the energy release from coal gradually decreases with time. The mechanical degradation of coal due to burning was simulated by removing the burned zone from the calculation after a specific time, which depended on zone size and type of coal. In this study, it was found that the maximum temperature at the burning zone was always less than $1000^{\circ} \mathrm{C}$, which agrees with previous research carried out for other UCG trials. The size of the burning zone was predicted to spread about $15 \mathrm{~m}$ laterally after 20 days of burning. Ground subsidence was evaluated for single and multiple (parallel) panel simulations; subsidence at the top of the numerical mesh, corresponding to a depth of $395 \mathrm{~m}$ below the surface, ranged from $23 \mathrm{~mm}$ for a single panel to $85 \mathrm{~mm}$ for seven panels. The degradation of mechanical properties of the rock surrounding the burned zone due to heating was found to have a marginal effect on the ground subsidence when parallel burning was carried out. The numerical modelling results obtained from this study may provide guidance for the design and operation of UCG processes.
\end{abstract}

Keywords: Coal, underground coal gasification, numerical modelling, calorific value, parallel burning.

\section{INTRODUCTION}

The consumption of energy in the world continues to rise. According to the International Energy Agency (2012), global energy consumption will increase by over one-third by 2035 and fossil fuels are still dominating the global energy mix. However, due to climate change and a finite supply of fossil fuels, the use of alternatives such as geothermal energy, wind power, and solar power are set to increase (Bai et al., 2016). There is evidence that climate change is caused by anthropogenic greenhouse gas emissions, especially from fossil energy combustion (Ishida et al., 2014). Therefore, one of the main concerns of energy obtained from the burning of coal is that of the carbon footprint. According to Hancheng et al. (2016), it is crucial that technologies that are more energy efficient and/or that can provide energy with lower carbon emissions are adopted in order to mitigate climate change effects.

The extraction of energy in a sustainable form from unworked areas of coal deposits in the subsurface is challenging. Traditional coal mining methods emit considerable levels of $\mathrm{CO}_{2}$ to the environment from the machinery working a mining site. Underground coal gasification (UCG) is a promising option for extracting energy from coal in unworked areas of the subsurface (Imran et al., 2014). The process also provides a solution to obtain the coal energy of a thin coal seam that cannot be extracted by conventional methods. According to Bhutto et al. (2013), UCG is a combination of mining, exploitation, and gasification that eliminates the need for mining and can be used in deep or steeply dipping, un-mineable coal seams. Therefore, the UCG process offers a promising option to obtain energy from coal in a more environmentally friendly manner than 
traditional coal mining.

UCG was first trialled as early as 1868 by the German scientist Sir William Siemens; Anson G. Betts obtained the patent for UCG in 1909 (Bielowicz and Kasiński 2014). The first UCG field test program in England was carried out by Ramsey in 1912 (Bhutto et al., 2013). Several other UCG trials have been carried out in other countries, e.g. in the former Union of Soviet Socialist Republics (USSR) (Derbin et al., 2015); in the United States (Klimenko, 2009), and in China (Creedy et al., 2004).

One method to reduce greenhouse gas effects is the storage of $\mathrm{CO}_{2}$ in the subsurface. The selection of a suitable site for $\mathrm{CO}_{2}$ storage depends on many factors (Lamas and Cámara, 2014). According to Durucan et al. (2014), factors such as geomechanical properties, geological structures, cap rock behaviour, hydrogeology, depth, and tectonic activities are the main factors that need to be considered for storing $\mathrm{CO}_{2}$. The selection of the UCG site also fulfils some of the factors that are necessary for $\mathrm{CO}_{2}$ storage. The UCG process leaves a cavity in the subsurface which could be used for the storage of $\mathrm{CO}_{2}$. Therefore, another significant potential benefit of coal gasification is that the created cavity could be used for the capture of $\mathrm{CO}_{2}$ and its sequestration (Sarhosisa, et al., 2013).

The UCG process can be carried out in the field using several techniques. The fundamental methodology for UCG involves two wells, one serving as the injection well and the other as the production well (Figure 1). Four distinct phases can be identified in the coal gasification process. During the first phase, drilling of the injection and production wells from the surface to the coal seam is carried out. In the second phase, establishment of a highly permeable path between the two wells is created/maintained. Methods such as hydraulic fracturing, electro-linkage, explosives, and in seam linkages can be incorporated for this purpose. A detailed description of the methods is given in Blinderman et al. (2008) and Friedmann et al., (2009). Air and/or oxygen is injected through the injection well to start the ignition of coal in the third phase. Finally, in the fourth phase, the extraction of syngas by the production well is carried out. A detailed description of the in-situ gasification process is presented by Shirsat (1989).

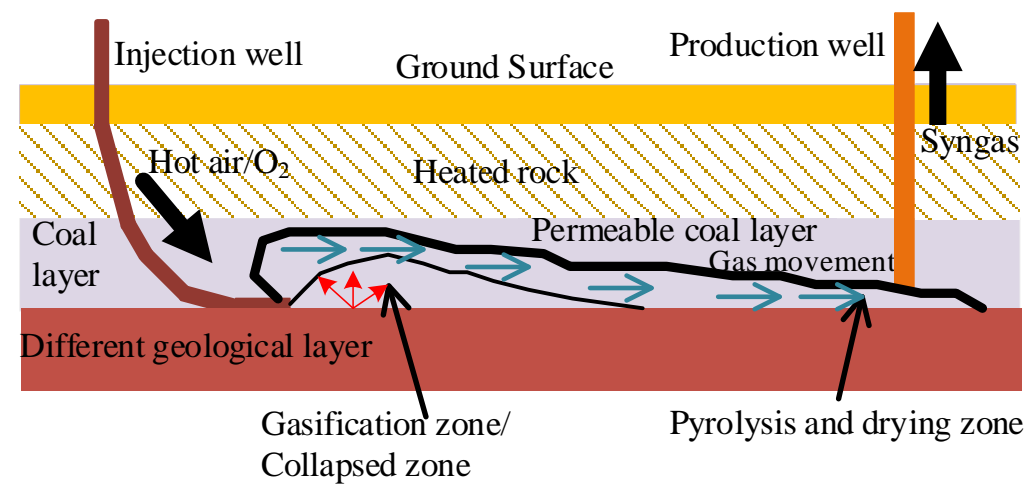

Figure 1-Typical arrangement of a UCG site (modified after Naghouni, 2013).

One of the main concerns of the UCG process is the ground induced subsidence. The effects of coal gasification was studied by Yang et al. (2014) using a numerical model for coupled thermal and mechanical responses to estimate ground subsidence. The finite element model, built in ABAQUS, simulated coal gasification at a depth of $1200 \mathrm{~m}$ in a $100 \mathrm{~m}$ thick coal seam. Several geological layers were presented in their numerical model to simulate real ground conditions. Laboratory measured geomechanical properties at room temperature were assigned to each geological layer. However, the study carried out by Ranjith et al. (2012) demonstrated that temperature had a significant effect on rock properties. According to the Yang et al. (2014) model, which assumed constant properties, the surface subsidence after three days of gasification was $0.08 \mathrm{~mm}$.

A thermal-mechanical coupled model in FLAC-3D, developed by Najafi et al. (2014), provided an estimate of the protection 
of the pillar during the UCG process. Geomechanical properties assigned to the model were based on previously published data (Tian, 2013). The heating effect due to coal gasification was simulated by applying a fixed temperature of $1500^{\circ} \mathrm{C}$ and $1200^{\circ} \mathrm{C}$ to the upper and lower boundaries of the gasification cavity, respectively. However, during the gasification process, it is not realistic to assume fixed temperatures for the boundaries; temperatures will vary around the gasification area depending on the emission of energy due to coal burning.

A fully coupled thermal-hydraulic-mechanical (T-H-M) model was developed by Xia et al. (2014) to evaluate the coal mechanical deformation, gas flow and transport, and heat transport using COMSOL. The complex interactions of different phases were defined through a suite of coal property models. The models included the following properties: (1) coal porosity; (2) coal permeability; (3) gas equation-of-state; and (4) self-heating models. By using their oxygen consumption model, they found that during coal-oxidation heating, the oxygen concentration has an "S-type" downwards trend, whereas the heating temperature of coal and the gas velocity show "S-type" upwards trends. One of the significant drawbacks of their model is that it is comparatively very small compared to a real coal gasification chamber and it may not be possible to simulate a real field scale scenario with available computational power.

The industrial application of UCG is carried out with several parallel burning panels, as illustrated in Figure 2, which enhances the gas production considerably compared to a single panel (Ekneligoda et al., 2015). One of the major concerns of parallel burning is induced ground subsidence. The selection of distance between parallel burning panels should be made after a thorough study of the effect of the coal burning process on ground subsidence.

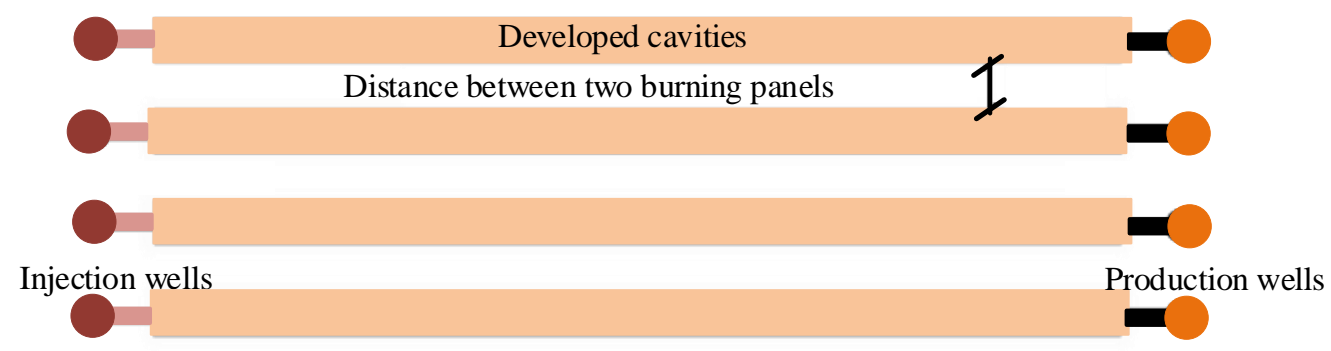

Figure 2-Plan view of a multi-panel industrial application of UCG.

In this study, numerical models were created using FLAC-3D to capture the geotechnical situation during the in-situ coal burning process at the Wieczorek UCG trial site in Poland. The model incorporates the variation of temperature in the cavity, which gradually decays with energy emission, backward movement of the burning head (from extraction to injection well), and temperature dependant material properties (Ekneligoda et al., 2015). Several laboratory experiments were conducted to measure the geomechanical properties of the relevant rock material at high temperature, which were incorporated in the numerical model. The numerical analyses were conducted in two stages. In Stage 1, the numerical model included a section near the UCG panel which was assigned a coupled thermal-mechanical constitutive relationship. Stage 2 involved a similar but more computationally efficient mechanical-only numerical model that incorporated results of maximum cavity size from Stage 1 in order to evaluate the worst-case scenario of ground movements from single and multiple UCG panels.

\section{DETAILS OF NUMERICAL MODEL}

\subsection{Model geometry}

The FLAC-3D mesh was developed based on the geological profile at the Wieczorek UCG trial site in Poland. The mesh was fixed horizontally and free vertically along all vertical boundaries (representing planes of symmetry). The bottom boundary was fixed in the vertical direction but free horizontally. 
An initial analysis was conducted taking into consideration only the mechanical response of the model due to the sudden removal of a zone of coal with dimensions length $Y=60 \mathrm{~m}$, width $X=12 \mathrm{~m}$, and depth $\mathrm{Z}=6 \mathrm{~m}$ located at a depth of $510 \mathrm{~m}$. The thickness of strata modelled above the coal seam was adjusted until a reasonable magnitude of settlement $(<25 \mathrm{~mm})$ was observed at the top of the model due to the excavation of the zone of coal. This factor was exploited in selecting the final dimensions of the model: $\mathrm{X}=100 \mathrm{~m}, \mathrm{Y}=60 \mathrm{~m}$, and $\mathrm{Z}=94 \mathrm{~m}$ (Figure 3a). A vertical stress of $8.98 \mathrm{MPa}$ was applied to the top of the model to represent the pressure from $395 \mathrm{~m}$ of overburden above the top surface of the model. This modelling procedure represents a worst case scenario since the coal burning process is more gradual, thereby allowing stress redistribution during the UCG.

The Stage 1 model, where the coupled thermal-mechanical constitutive behaviour was included, is illustrated in Figure 3 a. Different mesh sizes were assigned to different geological layers in the model. Mesh generation plays an important role in obtaining accurate results and achieving economy of computational time. As the expected temperature is very high (over $1000^{\circ} \mathrm{C}$ ) near the gasification area, a fine mesh was used in nearby zones. After a series of trial tests, a fine mesh with a size of $1 \mathrm{~m}$ (burning head direction) $\times 0.5 \mathrm{~m}$ (perpendicular to burning head) $\times 0.5 \mathrm{~m}$ (vertical direction) was assigned to the coal seam. Selecting a smaller size of element would capture the coal burning process in a more accurate manner, however, with the available computing power this would have led to excessively long computational time. Each element was assumed to satisfy the Mohr-Coulomb failure criterion. Exploiting the symmetry of the problem, only half of the geologic section was modelled. In this study, it was assumed that all rock strata were homogenous and were isotropic in terms of mechanical and thermal behaviour. The effects of methane and water within the coal were ignored. The geothermal gradient in the Wieczorek area is very low; therefore, a constant temperature was assigned to the model for thermal calculations. For the right-hand side (i.e. maximum $\mathrm{X}$ ) and bottom of the model, a constant temperature $\left(50^{\circ} \mathrm{C}\right)$ was set as the thermal boundary condition. Symmetry (for temperature) was used as the boundary condition for the left hand side (i.e. $\mathrm{X}=0$ ) of the model (i.e. a no heat flux (Neumann) boundary condition). Only an initial temperature boundary condition was assigned to the maximum and minimum Y planes as the temperature was free to rise along these planes during the calculation process.

A series of trial numerical model studies showed that temperature did not spread more than $8 \mathrm{~m}$ from the source during the gasification process because the thermal conductivity of the surrounding rocks is very low (on the order of $10^{-2} \mathrm{~W} / \mathrm{m}$ ). This feature helped simplify the model by only performing a coupled thermal-mechanical analysis within zones near the source $(X=100 \mathrm{~m}, Y=60 \mathrm{~m}, \mathrm{Z}=20.5 \mathrm{~m}$ height, centred on the coal seam, as shown in Figure 3a, where layers of shale and sand stone exist). Only a mechanical analysis was performed for the rest of the model.

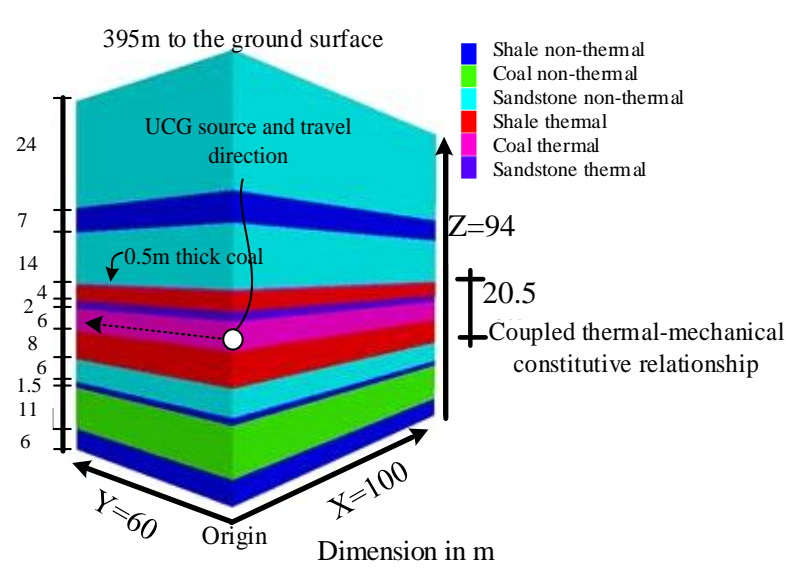

(a)

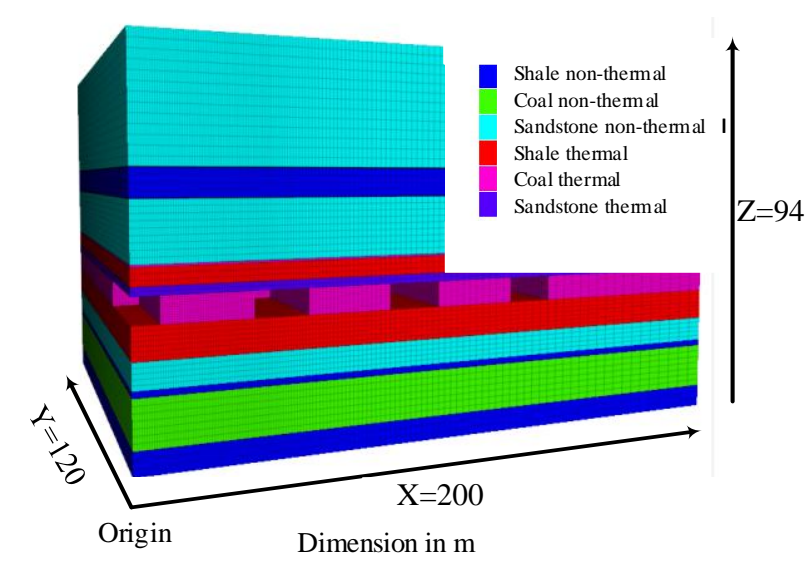

(b)

Figure 3-Details of FLAC3D mesh: a) Stage 1 model, b) Stage 2 model for multiple panels. 
In Stage 2 models, the lateral dimensions of the mesh were increased to $X=200 \mathrm{~m}$ and $\mathrm{Y}=120 \mathrm{~m}$ in order to ensure that boundary effects on displacements were minimized, as illustrated in Figure $3 \mathrm{~b}$. This model used standard mechanical constitutive relationships in order to decrease computational time. Analyses were conducted to evaluate ground movements for worst-case UCG scenarios for single and multiple panels. The cavity dimensions were selected based on 15 day burning results obtained from Stage 1 analyses which was taken as $30 \mathrm{~m}(\mathrm{Y})$ x $12 \mathrm{~m}(\mathrm{X})$ × $6 \mathrm{~m}(\mathrm{Z})$. This model was deemed to represent the worst-case scenario because it included an estimate of maximum cavity size after long term burning (based on Stage 1 results) and also because it does not redistribute stresses gradually with excavation.

\subsection{Temperature effect on material properties}

Constant material properties (independent of temperature) were used in the areas where only a mechanical analysis was performed (i.e. outside the $20.5 \mathrm{~m}$ thick coupled zone near to the coal seam). The area close to the gasification coal seam may experience temperatures of at least $1000^{\circ} \mathrm{C}$ (Bhutto et al., 2013, Akbarzadeh and Chalaturnyk, 2014). Several researchers have shown the effect of temperature on rock properties (Ranjith et al. 2012, Lintao et al., 2017) where distinct temperature ranges were identified over which the behaviour of sandstones varied.

As part of this study, a laboratory testing programme was conducted at the University of Nottingham to evaluate the effect of temperature on the geotechnical properties of the rocks near the coal seam at the Wieczorek site (see also Lintao et al., 2017). Core samples of both sandstones and shale were tested according to ISRM guidelines (1978). Before the experiments, samples were treated to either $20^{\circ} \mathrm{C}, 400^{\circ} \mathrm{C}, 800^{\circ} \mathrm{C}$, or $1000^{\circ} \mathrm{C}$ for $24 \mathrm{~h}$ and then allowed to cool for an additional $24 \mathrm{~h}$. Unfortunately, shale samples were poor in quality due core disking, which limited the data obtained for shale; the heated shale samples disintegrated after heating above $150^{\circ} \mathrm{C}$. As a result, shale properties at higher temperatures were based on data obtained from the literature (detailed below).

For sandstone, X-ray diffraction tests were performed which helped to identify distinct chemical and mineralogical changes within the rock resulting from heat treatment. The data showed that the main mineral constituents of the sandstone at $20^{\circ} \mathrm{C}$ were quartz, kaolinite, orthoclase, and illite. Samples treated to $800^{\circ} \mathrm{C}$ no longer showed the presence of kaolinite, and at $800^{\circ} \mathrm{C}$ mullite formed (Yang-Lintao et al., 2017). The changes in the sandstone samples can be observed visually in Figure 4 . The heat-treated samples were then tested by multi-stage triaxial testing to obtain stress-strain data; Figure 5 shows averaged results from four samples treated to each temperature.

The test data for the sandstone showed an $8 \%$ increase of Young's modulus from $20^{\circ} \mathrm{C}$ to $400^{\circ} \mathrm{C}$, a $13 \%$ reduction at $800^{\circ} \mathrm{C}$ compared to $20^{\circ} \mathrm{C}$, and an $18 \%$ reduction at $1000^{\circ} \mathrm{C}$ compared to $20^{\circ} \mathrm{C}$. The following simplified method was used to assign elastic modulus at different temperatures to the numerical model: $\mathrm{E}^{\circ} \mathrm{E}_{20}$ (where $\mathrm{E}_{20}$ is the value at $20^{\circ} \mathrm{C}$ ) was 1.1 at $400^{\circ} \mathrm{C}, 0.9$ at $800^{\circ} \mathrm{C}$, and 0.8 at $1000^{\circ} \mathrm{C}$. A reduction of sample density was also observed in the sandstone compared to $20^{\circ} \mathrm{C}$, which also was taken into consideration in the numerical model (see Table 1). 


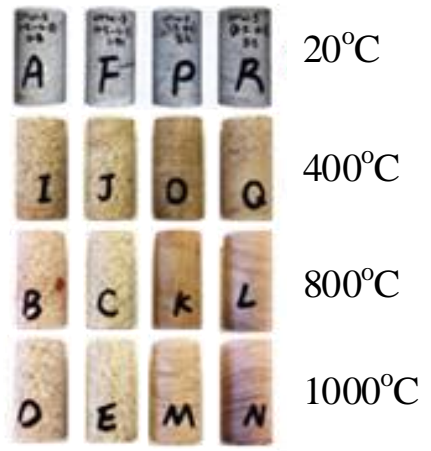

Figure 4-Samples treated at different temperatures

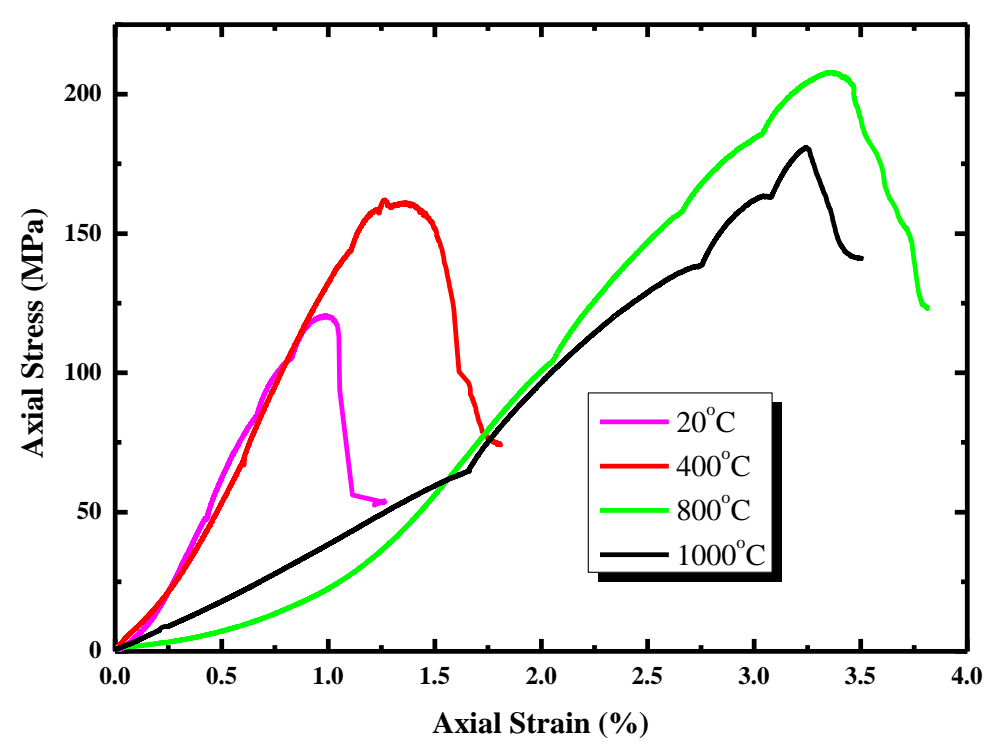

Figure 5-The average multistage triaxial results for a selected coarse sandstone sample.

The data (Figure 5) were also used for the derivation of cohesion and friction angles at different temperatures. The derived values of cohesion and friction angle at each temperature are given in Table 1. Due to lack of experimental data, it was assumed that the variation of properties of shale followed the same trend that was measured for the sandstone. Shale properties at room temperature were obtained from Ranjith et al., 2012; Sun et al., 2016; Rybacki et al., 2015. Although this may seem like a limitation of the model, its effect on modelling results was judged to be minimal because of the arrangement of geological layers at the site, where sandstone exists just above the coal layer. Numerical results indicated that temperatures never rose above $200^{\circ} \mathrm{C}$ in the upper shale layer. Therefore, it can be reasonably assumed that the thermal variation of properties of the sandstone have the dominant effect on results.

In order to investigate temperature effects on the tensile strength of sandstone, Brazilian disk tests were carried out on heat treated samples of $40 \mathrm{~mm}$ diameter and $20 \mathrm{~mm}$ length. Figure 6 illustrates the variation of average tensile strength of the sandstone samples. The data generally show a gradual reduction of the tensile strength with temperature increase. The maximum tensile strength of $4.25 \mathrm{MPa}$ was obtained at room temperature $\left(20^{\circ} \mathrm{C}\right)$, whereas the minimum value of $1.4 \mathrm{MPa}$ was obtained from the samples treated at $800^{\circ} \mathrm{C}$. 


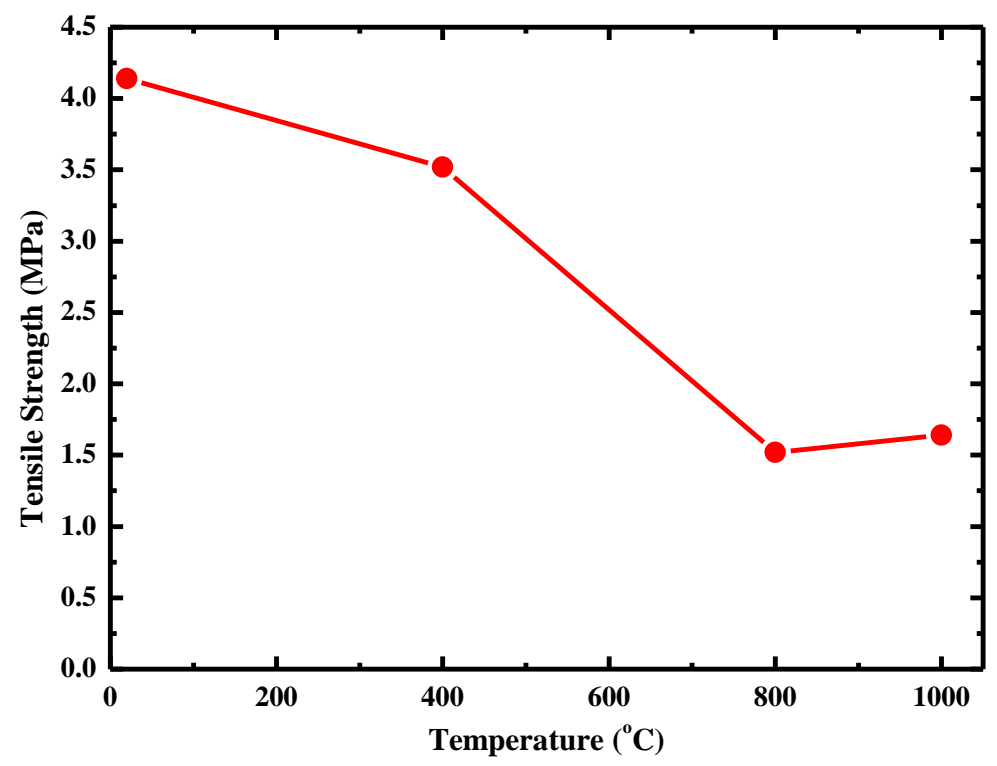

Figure 6-Variation of tensile strength of sandstone

Table 1 also shows data for the coal, which were collected from the available literature (Booth et al., 2016; Ranjith et al., 2012; Rybacki et al., 2015; Johnston, 1987). The variation of the coal properties (the magnitude of property variation) with temperature becomes meaningless after it starts burning at $200^{\circ} \mathrm{C}$. Therefore, a null property was assigned to burned zones after 1h. It was assumed that the variation of tensile strength of shale was similar to that of sandstone. This approximation has a marginal effect on final results as there were very few tensile failure zones (less $0.01 \%$ of the total number of zones) in the sandstone layer near the gasified area. Table 1 illustrates the properties used in the numerical study.

Table 1- Material properties used in the numerical model

\begin{tabular}{|c|c|c|c|c|c|c|c|c|}
\hline layer & Geological & $\begin{array}{l}\text { Temp } \\
\left({ }^{\circ} \mathrm{C}\right)\end{array}$ & $\begin{array}{l}\text { Cohesion } \\
\text { (MPa) }\end{array}$ & $\begin{array}{c}\text { Friction } \\
\text { angle } \\
\left(^{\circ}\right)\end{array}$ & $\begin{array}{c}\text { Tensile } \\
\text { strength } \\
(\mathrm{MPa})\end{array}$ & $\begin{array}{c}\text { Elastic } \\
\text { modulus } \\
(\mathrm{GPa})\end{array}$ & $\begin{array}{l}\text { Poisson's } \\
\text { ratio }\end{array}$ & $\begin{array}{l}\text { Density } \\
\left(\mathrm{kg} / \mathrm{m}^{3}\right)\end{array}$ \\
\hline \multirow{4}{*}{\multicolumn{2}{|c|}{ Shale }} & $>20$ & 30 & 32 & 7.5 & 1.4 & 0.3 & 2400 \\
\hline & & $>400$ & 37.8 & 34.88 & 7.13 & 1.54 & 0.3 & 2304 \\
\hline & & $>800$ & 37.8 & 37.12 & 2.63 & 1.26 & 0.3 & 2200 \\
\hline & & $>1000$ & 30.98 & 37.76 & 2.81 & 1.12 & 0.3 & 2160 \\
\hline Coal & & $>20$ & 10 & 30 & 4 & 1 & 0.35 & 1350 \\
\hline \multirow{4}{*}{\multicolumn{2}{|c|}{ Sandstone }} & $>20$ & 8 & 45 & 4 & 1.5 & 0.3 & 2350 \\
\hline & & $>400$ & 10.05 & 49.05 & 3.8 & 1.65 & 0.3 & 2200 \\
\hline & & $>800$ & 10.05 & 52.2 & 1.4 & 1.35 & 0.3 & 2150 \\
\hline & & $>1000$ & 8.25 & 53.1 & 1.5 & 1.2 & 0.3 & 2100 \\
\hline
\end{tabular}




\section{SPECIAL FEATURES OF THE COUPLED NUMERICAL MODEL}

\subsection{Simulation of coal burning}

The coal burning process emits energy and it is important to take into account this energy emission in the numerical model simulation of the UCG process. In this work, the energy balance equation in zones representing coal was modified such that when one zone started burning (at $200^{\circ} \mathrm{C}$ ) an additional source term was added.

One of the key features of the applied source term is that it does not stay constant but decays gradually with time. In this way, the coal burning process was numerically represented. The source term was determined in relation to the calorific value of the coal, which depends on several factors, such as amount of carbon, hydrogen, and oxygen. In this study, it was assumed that the calorific value of the coal in the Wieczorek area was $2000 \mathrm{MJ} / \mathrm{kg}$ (Rajwa et al., 2017). The modified energy equation for the coal layer can be expressed as:

$$
q_{i, i}+q_{v(t)}=C_{p} \rho \frac{\partial T}{\partial t}
$$

where $T$ is temperature, $t$ is time, $q_{v}$ is the volumetric heat-source intensity $\left[\mathrm{W} / \mathrm{m}^{3}\right]$, and the right-hand side of the expression is the heat stored per unit volume $\left[\mathrm{J} / \mathrm{m}^{3}\right]$. The parameters $C_{p}$ and $\rho$ are specific heat capacity and density, respectively, and $q_{i, i}$ is the heat-flux vector $\left[\mathrm{W} / \mathrm{m}^{2}\right]$ derived with respect to the spatial coordinate. A simplification of $q_{i, i}$ is presented as:

$$
\begin{gathered}
q_{i, i}=\frac{\partial q_{x}}{\partial x}+\frac{\partial q_{y}}{\partial y}+\frac{\partial q_{z}}{\partial z} \\
q_{i, i}=k_{x} \frac{\partial^{2} T_{x}}{\partial x^{2}}+k_{y} \frac{\partial^{2} T_{y}}{\partial y^{2}}+k_{z} \frac{\partial^{2} T_{z}}{\partial z^{2}}
\end{gathered}
$$

where $k_{x}, k_{y}$ and $k_{z}$ are the thermal conductivities in each direction. In the present model, an isotropic thermal conductivity (i.e. same in every direction) was considered. Thermal conductivity also depends on temperature, however its variation for the conditions modelled here is relatively low, hence it was assumed that thermal conductivity is independent of temperature (Zao et al., 2016).

The source term $q_{v}$ was assumed to be zero if the temperature of a zone in the coal was less than $200^{\circ} \mathrm{C}$. The ignition temperature of $200^{\circ} \mathrm{C}$ was based on the work of researchers that dealt with the spontaneous combustion of coal (Xia et al., 2014; Kim and Sohn, 2012). If the temperature in the coal seam was greater than $200^{\circ} \mathrm{C}$, the source term was modified as:

$$
q_{v(t)}=A e^{-B t}
$$

where $A$ and $B$ are constants that depend on the calorific value of coal and the combustion time period

One of the important aspects of the coal burning process is the duration, which is related to the chemical composition of coal and the availability of oxygen. During the UCG process, oxygen is supplied in a controlled manner. Therefore, the ignition period and the release of embedded energy of coal in UCG is not the same as the ignition of coal under normal atmospheric conditions. In order to determine the two unknowns in the Eq. 3 (i.e. $A$ and $B$ ), two assumptions were adopted. The first was that $20 \%$ of the embedded energy is released during the initial 10 s of burning. The second was that a loss of $90 \%$ of the embedded energy represents the complete burning of the coal, which takes a duration of 1 hour (Glushkov et al., 2017). These two assumptions were used to determine the parameters $A$ and $B$ for each element in the coal region. 
Note that these parameters can be altered in the numerical model according to the type of coal being considered; the values adopted in this study are illustrative but not unique. One of the ways to estimate the accuracy of the above assumptions is to measure the temperature inside the cavity. Indirect measurements have shown that the maximum temperature inside a UCG cavity is about $1000^{\circ} \mathrm{C}$ (Rajwa et al., 2017); this numerical model used here indicated a maximum temperature that was always less than $1000^{\circ} \mathrm{C}$.

As stated above, Eq. 3 directly relates to the calorific value of coal and the zone size of the domain. Therefore, the source term is a function of time, calorific value and the zone size of the domain. For the remaining zones in the domain (sandstone and shale), the energy equation given by Eq. 1 was used, keeping $q_{v}=0$. For the mechanical calculation, any zone of coal that released $90 \%$ of its energy was considered to be disintegrated and set to a null zone within the model. In this way, the model could capture the gradual development of the cavity as the coal burned.

The burning process can be carried out in a number of different manners in a UCG operation. The movement of the burning head backwards from the extraction well towards the injection well, known as the continuous retraction injection point process (CRIP), was modelled in this work. In the model, the source (burning head) was moved at a relatively slow speed of $1 \mathrm{~m} /$ day and the temperature of the burning head was maintained at $1000^{\circ} \mathrm{C}$.

\subsection{Governing equations}

In the numerical simulation, the additional stress components due to heat transfer were coupled to the mechanical stress calculation. It is important to note that the coupling occurs only in one direction, i.e. temperature changes affect mechanical stresses, but mechanical stress changes do not affect temperature. The coupled equation can be presented in the simple form shown in Eq. 4. Assuming that the thermal expansion/contraction is isotropic, the stress-strain relationship is non-isothermal. This coupling was performed at each calculation step by calling the original mechanical module and the thermal module in FLAC using the Fish language available in FLAC (Itasca, 2014).

$$
\frac{\partial \sigma_{i j}}{\partial t}=2 G\left[\frac{\partial \varepsilon_{i j}}{\partial t}-\alpha_{t} \frac{\partial T}{\partial t} \delta_{i j}\right]+\left(K-\frac{2}{3} G\right)\left[\frac{\partial \varepsilon_{k k}}{\partial t}-3 \alpha_{t} \frac{\partial T}{\partial t}\right] \delta_{i j}
$$

where $\mathrm{G}=\mathrm{E} / 2(1+v)$ (shear modulus), $\mathrm{K}=\mathrm{E} / 3(1-2 v)$ (bulk modulus), $\varepsilon_{\mathrm{kk}}=\varepsilon_{11}+\varepsilon_{22}+\varepsilon_{33}, \sigma_{\mathrm{ij}}$ is the component of the total stress tensor, $\varepsilon_{\mathrm{ij}}$ is the component of the total strain tensor, E is Young's modulus, $v$ is Poisson's ratio, $\delta_{\mathrm{ij}}$ is the Kronecker delta, $\mathrm{T}$ is temperature in degrees Celsius, and $\alpha_{\mathrm{T}}$ is the thermal expansion coefficient.

The equations of equilibrium and the strain-displacement relations can be expressed as;

$$
\begin{gathered}
\sigma_{i j, j}+f_{i}=0 \\
\varepsilon_{i j}=\frac{1}{2}\left(u_{i, j}+u_{j, i}\right)
\end{gathered}
$$

where $f_{i}$ and $u_{i}(i=x, y, z)$ are the components of the net body force and displacement in the $i$-direction, respectively. A comma followed by subscripts represents the differentiation with respect to spatial coordinates and repeated indices in the same values imply summation over the range of the indices (Detournay and Cheng,1993; Zhang et al., 2008). 


\section{RESULTS AND DISCUSSION}

\subsection{Stage 1 model}

\section{Temperature distribution}

The spread of the temperature in the model was governed by the thermal conductivity of the surrounding layer of sandstone. A rise of temperature in the vertical direction at different geological layers was observed up to approximately $8 \mathrm{~m}$ after 20 days of coal burning. This temperature distribution verified that the coupling calculation was only required in the area near to the source. Analysis of the temperature distribution inside the cavity showed that cavity temperature was always less than $1000^{\circ} \mathrm{C}$ during gasification. As the thermal properties of the layers are relatively low, the development of temperature is controlled mostly by the energy emission due to coal burning.

\section{Coal burning and cavity development}

Gradual burning of the coal resulted in the development of a burn cavity. Figure 7 illustrates the development of the cavity over a period of 20 days (note that time is in terms of simulated burn days rather than run-time of the analyses). The width (perpendicular to the burning direction) of the cavity increased from $1.5 \mathrm{~m}$ after 1 day of burning to $7.5 \mathrm{~m}$ after 20 days (note that due to the symmetric nature of the model this represents a cavity width of $15 \mathrm{~m}$ ). Cavity development depends on the calorific value of the coal as well as the rate of movement of the burning head. Note that because the model is symmetric about the $\mathrm{X}=0$ plane, the total cavity width (in the $\mathrm{X}$-direction) is twice that shown in Figure 7.

The size of the zones (representing the coal) shown earlier in Figure 3 was $1 \times 0.5 \times 0.5 \mathrm{~m}(\mathrm{X} \times \mathrm{Y} \times \mathrm{Z})$. Cavity development took place when the average temperature of the zone increased above $200^{\circ} \mathrm{C}$. The analysis took approximately 22 days of computation to simulate 20 days of the burn process.
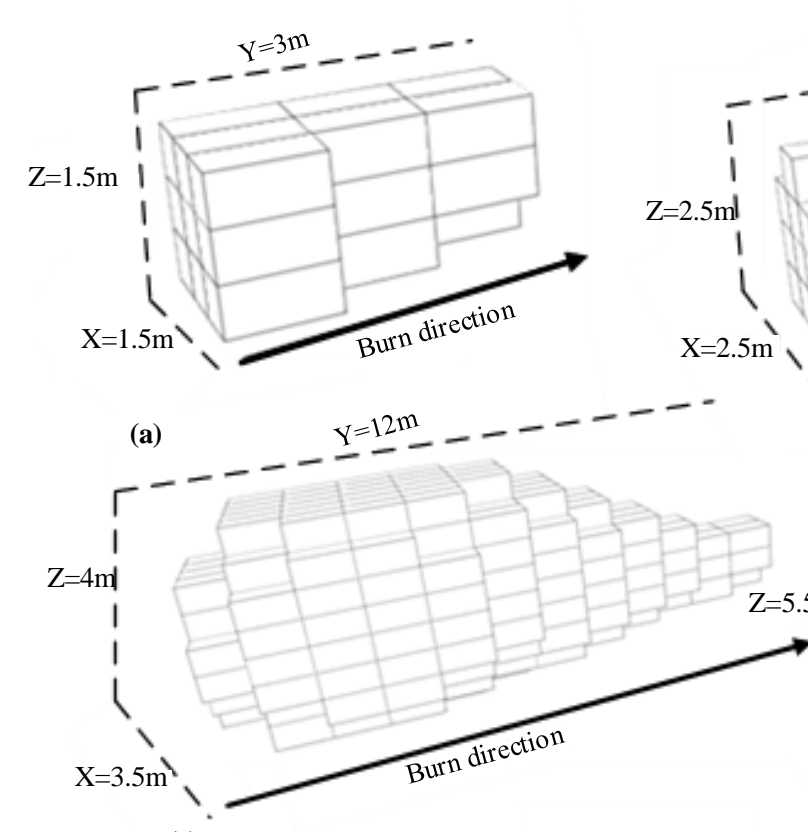

(c)

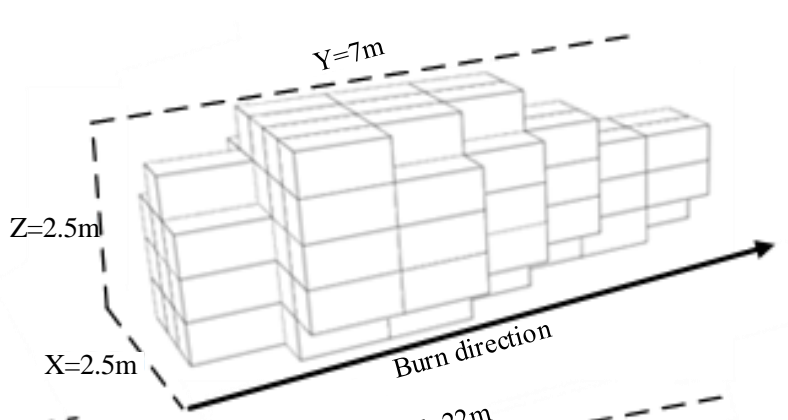

(b)

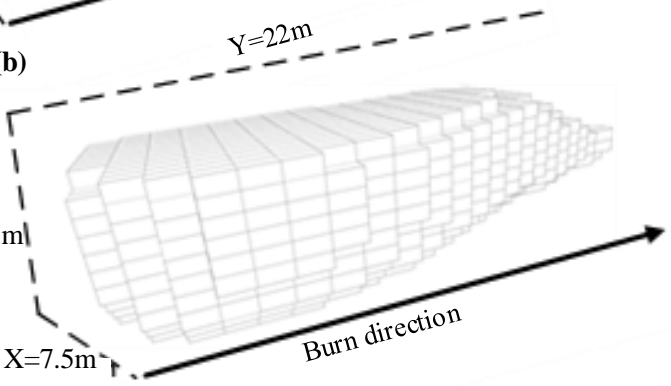

(d)

Figure 7-Cavity development after (a) 1, (b) 5, (c) 10, and (d) 20 days burning 


\subsection{Stage 2 model - parallel burning}

The coupled analysis results from the previous section enabled an estimation of the size of the burn cavity. A worst-case model was considered using the 20 day cavity size excavated instantaneously within the model. The size of the burning panel was $12(\mathrm{X}) \times 30(\mathrm{Y}) \times 6(\mathrm{Z}) \mathrm{m}$ in contrast to the gradually reducing lateral dimension of the real cavity. This scenario was then extended to consider the effects of parallel burning. The concept of parallel panel burning is crucial in the industrial application of UCG as the method can increase the rate of production of syngas. However, the selection of spacing should be carefully decided to avoid significant ground subsidence as smaller spacing between panels can fail leading to catastrophic ground subsidence. Analyses were done including five and seven (as shown in Figure 3b) burning panels to demonstrate the importance of panel spacing. The ground subsidence was modelled for different distances between panels, ranging from $5 \mathrm{~m}$ to $20 \mathrm{~m}$ (edge to edge distance) in steps of $5 \mathrm{~m}$.

The experimental data presented earlier showed that the maximum variation (degradation) of material properties was always less than $20 \%$ (except the tensile strength) for all tested temperatures. To evaluate the effect of material degradation on results, three sets of analyses were conducted: 'original property' using the $20^{\circ} \mathrm{C}$ values in Table 1 , a $10 \%$ reduction on properties, and a $20 \%$ reduction on properties. Figure 6 showed that tensile strength was affected by more than $20 \%$ by increased temperatures (hence the $20 \%$ reduction is an underestimation of its degradation), however tensile strength had a marginal effect on the overall subsidence values.

The variation of subsidence for the five and seven burning panel models for the three material sets is presented in Figure 8 . For the original properties, the subsidence at the top of the model directly above the gasification point (which is $395 \mathrm{~m}$ below the ground surface) was found to be $72 \mathrm{~mm}$ and $88 \mathrm{~mm}$ for the five and seven panel models, respectively, for a panel separation of $5 \mathrm{~m}$. Gradually deceasing ground subsidence was observed at this location when increasing the distance between the burning panels, reaching $40 \mathrm{~mm}$ and $42 \mathrm{~mm}$ at a separation of $20 \mathrm{~m}$ for the 5 and 7 panel analyses, respectively. The reduction of material properties by $10 \%$ is shown to have a minimal effect. For the $20 \%$ reduction case with 7 panels at a separation of $5 \mathrm{~m}$, the subsidence measured vertically above the centre point of the gasification panel increased by $19 \%$ (relative to original property) to $105 \mathrm{~mm}$.

It is important that UCG production installations (e.g. power/purification plants) be located on stable ground, hence the evaluation of a minimal distance from the panels to a 'safe' location is important. However, this requirement also yields additional cost due to the need for space, therefore it is important to select an optimum location for the installations. A maximum tolerable settlement for determining a 'safe' location is difficult to define since it depends on the vulnerability of the infrastructure under consideration. The numerical models described here involve various assumptions and uncertainties, which impacts on their ability to provide accurate 'absolute' predictions of settlements. However, in relative terms (i.e. comparing results from analyses with different inputs), the models should give a good evaluation of the effect of a change in a parameter value. This approach was used to provide an indication of how a 'safe distance' could vary for the different parallel burning scenarios considered. Figure 8 includes data of subsidence at a location $100 \mathrm{~m}$ offset (in the $\mathrm{x}$-direction, measured from $X=0$; refer to Figure 3). At $X=100 \mathrm{~m}$, the single panel original property analysis subsidence reached a value of $2.5 \mathrm{~mm}$. The original property results indicate a subsidence at $X=100 \mathrm{~m}$ of less than $8 \mathrm{~mm}$ for five panels at a separation of $5 \mathrm{~m}$, which gradually increases to about $14 \mathrm{~mm}$ for a $20 \mathrm{~m}$ panel separation; the equivalent values for the 7 panel analyses are $19 \mathrm{~mm}$ and $30 \mathrm{~mm}$. The reduction of material parameters does not have a significant effect on subsidence at $X=100 \mathrm{~m}$; for the 7 panel analyses with $20 \%$ property reduction, the settlements reached $23 \mathrm{~mm}$ and $36 \mathrm{~mm}$ for $5 \mathrm{~m}$ and $20 \mathrm{~m}$ panel spacings, respectively.

As a means of comparing results between single and multiple panel analyses, a reference settlement of $2.5 \mathrm{~mm}$ obtained at a location $100 \mathrm{~m}$ from the burn cavity $(\mathrm{X}=100 \mathrm{~m})$ for the single panel original property analysis was used and the lateral offset in the multiple panel models where settlement reached this value was found, as shown in Figure 9 (all models are for the 'original property'). This reference settlement of $2.5 \mathrm{~mm}$ is relatively low as a definition of tolerable settlement, however it is 
used here simply to allow comparison between model results. Figure 9(a) shows that the distance from the middle of the central panel (the plane of symmetry of the numerical model; $\mathrm{X}=0$ ) to where $2.5 \mathrm{~mm}$ subsidence occurs gradually increases with the spacing between panels for both 5 and 7 burning panels. Five panels with a spacing of $20 \mathrm{~m}$ requires a distance of $140 \mathrm{~m}$, whereas seven burning panels at the same spacing requires $176 \mathrm{~m}$. The results in Figure 9(a) include the effect of the size of the panels and the inter-panel spacing. Considering the distance from the outermost burn panel (in the x-direction), Figure 9(b) shows that the lateral distance from the outermost edge of the outermost burn panel to the location where subsidence reaches $2.5 \mathrm{~mm}$ is about $70 \mathrm{~m}$ and does not vary significantly within the various models. Both the original and $20 \%$ reduction properties yielded similar distance results with the variation not greater than $3 \%$ for both 5 and 7 burning panels. These results indicate that the impact of the variation of properties is more prominent close to the burning panels but the effect in locations remote from the burning panel are relatively small. 


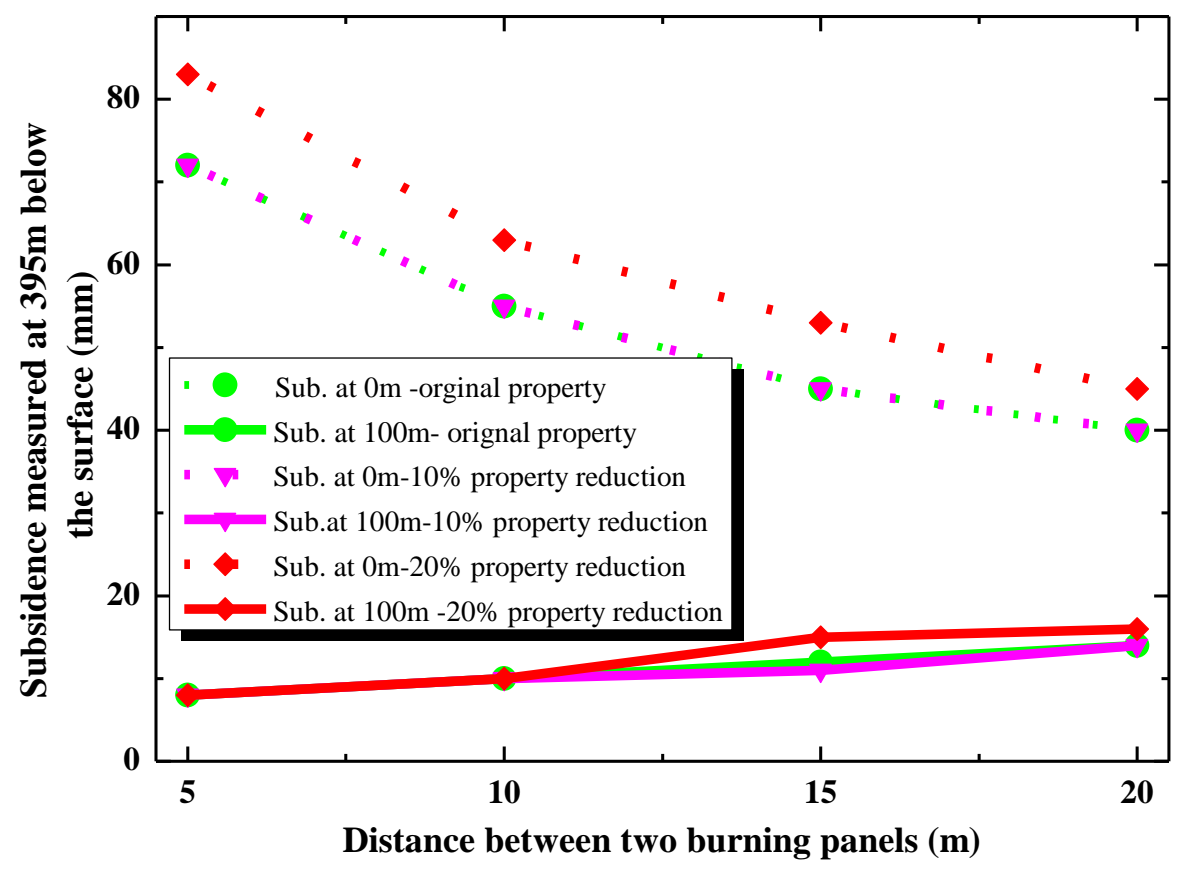

(a)

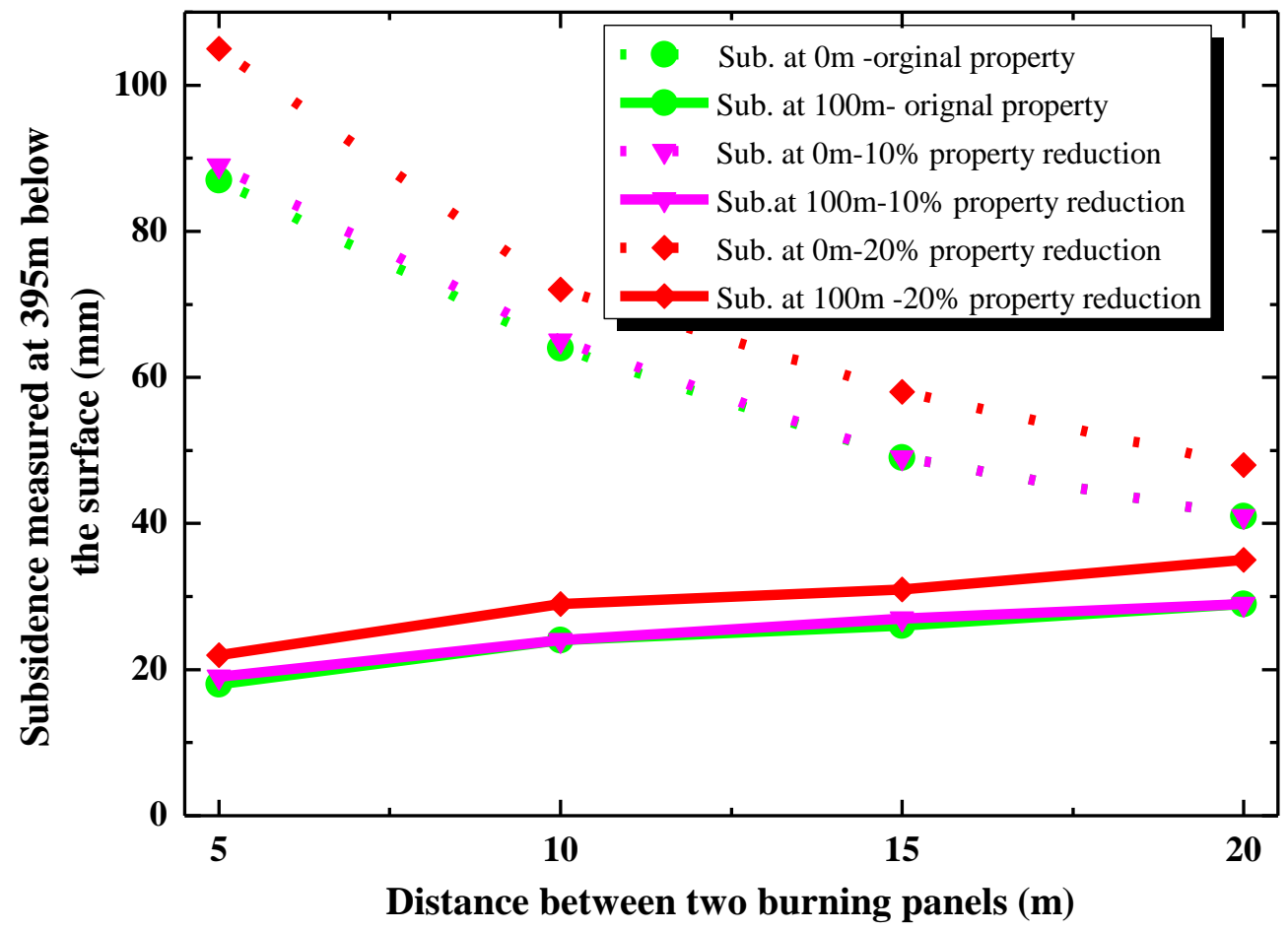

(b)

Figure 8-The variation of ground subsidence due the degradation of properties: (a) five burning panels, (b) seven burning panels. 


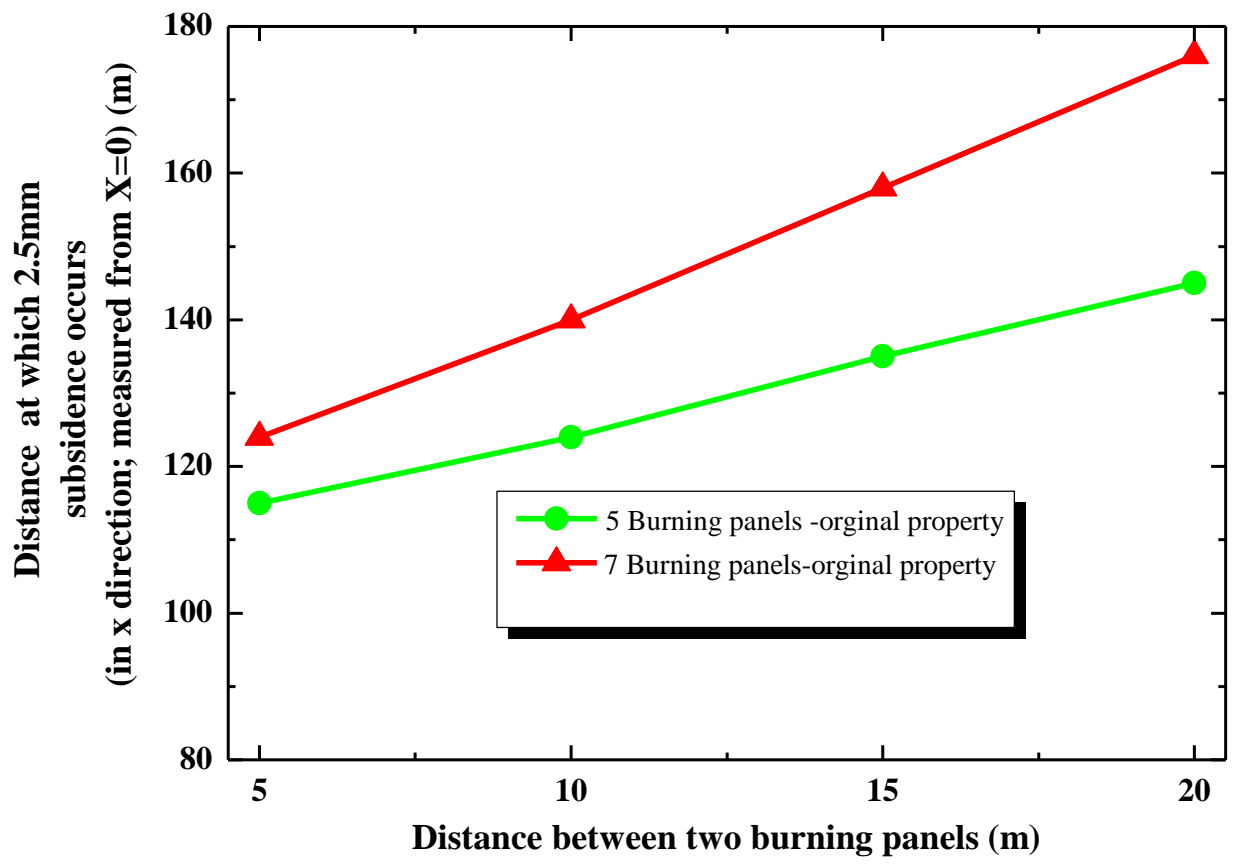

(a)

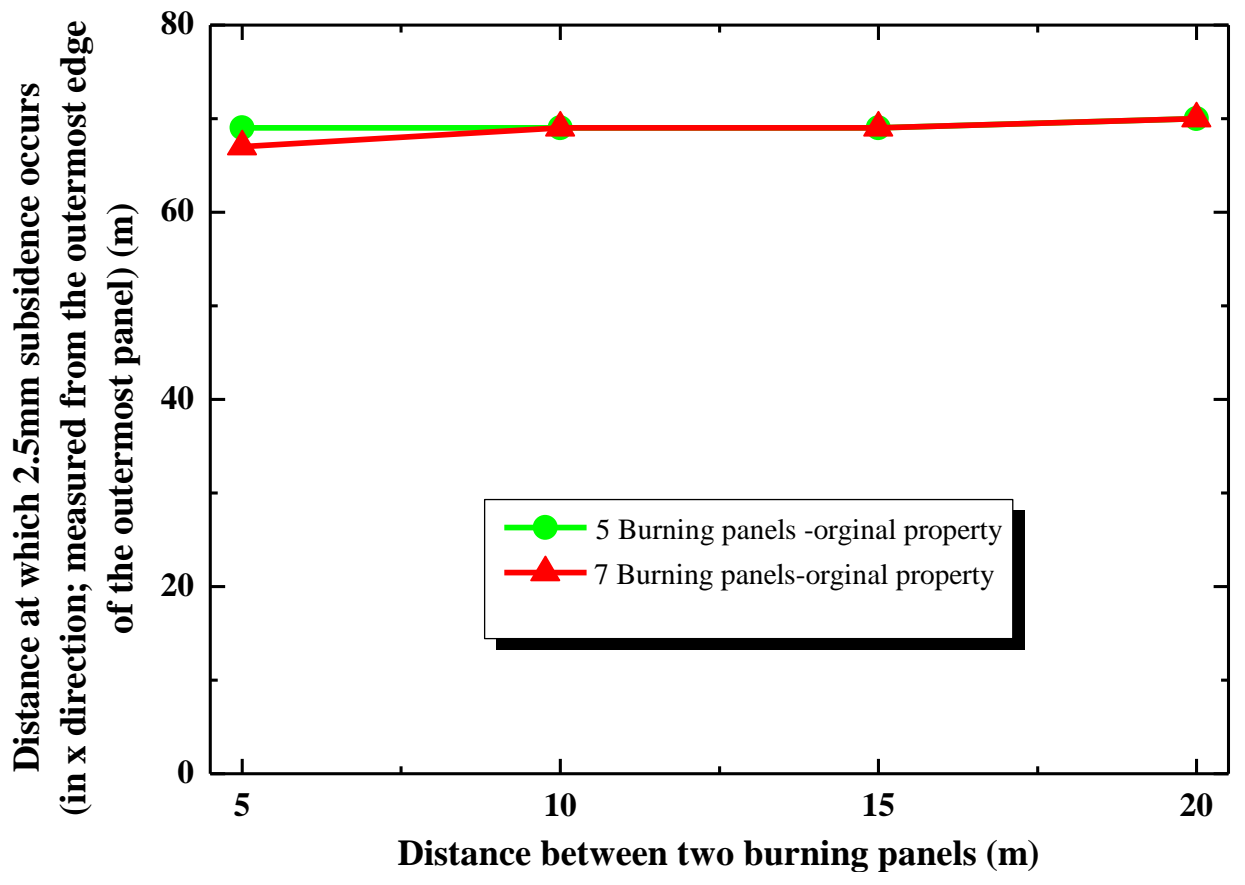

(b)

Figure 9- The variation of distance where $2.5 \mathrm{~mm}$ subsidence occurs for 5 and 7 burning panels. 


\section{CONCLUSIONS}

The paper presented details of a numerical model that was developed to analyse several key features that take place during the process of underground coal gasification. The model was developed based on the UCG trial site at the Wieczorek mine in Poland. Samples obtained from the site were obtained and laboratory tests were conducted to evaluate the effect of high temperatures (up to $1000^{\circ} \mathrm{C}$ ) on the mechanical properties of the rock, which were then included as input parameters for the numerical model. A coupled thermal-mechanical numerical model was developed to represent the UCG trial. The numerical analyses included a methodology to simulate the coal burning process with time and thereby allow an evaluation of the maximum size of the created burn cavity.

The maximum numerically derived temperature during the gasification process was estimated to be $1000^{\circ} \mathrm{C}$ inside the cavity. The maximum dimension of the cavity was predicted to be $22 \mathrm{~m}$ in the burning direction, $15 \mathrm{~m}$ perpendicular to the burning direction (laterally), and $5.5 \mathrm{~m}$ in the vertical direction after 20 days of gasification. A worst-case scenario study showed that the maximum displacement directly above the gasification point at the top of the mesh (at a depth of 395) was $23 \mathrm{~mm}$ and reduced to $2.5 \mathrm{~mm}$ at a distance $100 \mathrm{~m}$ away from the panel.

Parallel coal panel burning, which can enhance syngas recovery from a given area of coal reserves, was simulated with 5 and 7 panels at varying spacings. For the 5 panel model, the ground induced subsidence at the top of the model varied from $72 \mathrm{~mm}$ to $40 \mathrm{~mm}$ directly above the gasification when the distance between panels was varied from $5 \mathrm{~m}$ to $20 \mathrm{~m}$; the equivalent maximum ground subsidence ranged from $88 \mathrm{~mm}$ to $42 \mathrm{~mm}$ for the 7 panel model. The analyses also considered the effect of the reduction of strength and stiffness of the rock near to the UCG burn. For the 5 and 7 panel analyses with a spacing of $5 \mathrm{~m}$ and strength/stiffness properties reduced by $20 \%$, the subsidence at the top of the model directly above the gasification point increased to $87 \mathrm{~mm}$ and $105 \mathrm{~mm}$, an increase of $24 \%$ and $19 \%$, respectively.

As a means of comparing results between single and multiple panel analyses, the lateral distance from the middle of the central panel to where a predicted subsidence of $2.5 \mathrm{~mm}$ was obtained at the top of the numerical mesh were compared. For the five and seven panel analyses with $20 \mathrm{~m}$ spacing, the distance was $140 \mathrm{~m}$ and $176 \mathrm{~m}$, respectively. The distance from the outermost edge of the outermost panel to the location where $2.5 \mathrm{~mm}$ subsidence was obtained did not vary significantly between the model results. The reduction of rock properties was found to have marginal effects on this distance. The outcomes of this study are intended to help in the development of guidelines related to underground coal gasification.

\section{ACKNOWLEDGEMENTS}

The article was prepared based on research conducted within the Research Project: Underground Coal Gasification in operating mines and areas of high vulnerability (COGAR) funded by the European Commission Research Fund for Coal and Steel (RFCS) (Project No. RFC-PR-12005). 


\section{REFERENCES}

Akbarzadeh, H., Chalaturnyk, R. J., 2014. Structural changes in coal at elevated temperature pertinent to underground coal gasification: A review, International Journal of Coal Geology, 131, 126-146.

Bai, M., Zhang, Z., and Fu, X., 2016. A review on well integrity issues for CO2 geological storage and enhanced gas recovery, Renewable and Sustainable Energy Reviews, 59, 920-926.

Bhutto, A. W., Bazmi, A. A., and Zahedi, G., 2013. Underground coal gasification: From fundamentals to applications. Progress in Energy and Combustion Science, 39(1), 189-214.

Bielowicz, B., and Kasiński J.k., 2014. The possibility of underground gasification of lignite from Polish deposits, International Journal of Coal Geology, 131, 304-318.

Blinderman, M.S., Saulov, D.N., and Klimenko, A.Y., 2008. Energy optimization of reverse combustion linking in underground coal gasification, Journal of the Energy Institute 2, 81(1), 7-13.

Booth, A.J., Marshall, A.M., and Stace, R., 2016. Probabilistic analysis of a coal mine roadway including correlation control between model input parameters, Computers and Geotechnics, 74, 151-162.

Creedy, D.P., Garner, K., Oakey, J.E., and Abbott, D., 2004. Clean energy from underground coal gasification in China. Report No. COAL R250 DTI/Pub URN 03/1611.

Derbin, Y.G., Walker, J.C., Wanatowski, D., and Marshall, A.M., 2015. Soviet experience of underground coal gasification focusing on surface subsidence, Journal of Zhejiang University-Science A (Applied Physics \& Engineering), 16(10), 839850, doi: 10.1631/jzus.A1500013.

Detournay, E., and Cheng, A.H.D., 1993. Fundamentals of poroelasticity. In: Fairhurst C, editor. Compr rock eng, vol. 2. Oxford: Pergamon, 113-71.

Durucan, S., Korre, A., Shi, J., Idiens, M., StaĔczyk., K., Kapusta., K., Dabrowska, A.R., Kempka, T., Wolf, K., Younger, P., Zavsek, S., Poulsen, N. E., Bojda, D., Franzsen, S., Muresan, M., Gao, J., Beath, A., and Mastaler, M., 2014. TOPS: Technology options for coupled underground coal gasification and CO2 capture and storage, Energy Procedia 63, 5827-5835

Ekneligoda, T.C., Yang, L.T., Wanatowski, D., Marshall, A.M., and Stace, L.R., 2016. Modelling ground subsidence at an underground coal gasification site, 19th Southeast Asian Geotechnical Conference \& 2nd AGSSEA Conference (19SEAGC \& 2AGSSEA), Kuala Lumpur, 31 May.

Ekneligoda, T.C., Yang, L.-T., Wanatowski, D., Marshall, A.M., and Stace, L.R., 2015. A fully developed thermal mechanical coupled numerical model to capture the spontaneous coal combustion and its effect at Wiczorek site in Poland,7th international conference in mining science and technology, Xuzhou, China, 24-24 April.

Friedmann, S.J., Upadhye, R., and Kong, F.M., 2009. Prospects for underground coal gasification in carbon-constrained world. Energy Procedia; 1(1).

Glushkov, O.D., Kuznetsova, G. V, Chebochakova, D. A., Lyakhovskaya, O.E., Shlegela, N.E., Anufriev, I. S., Shadrin E.Y., 2017. Experimental study of coal dust ignition characteristics at oil-free start-up of coal-fired boilers. Applied Thermal Engineering 142, 371-379. 
Hancheng, D., Herran, D.S., Fujimori, S., and Masui, T., 2016. Key factors affecting long-term penetration of global onshore wind energy integrating top-down and bottom-up approaches, Renewable Energy, 85, 19-30.

Imran, M., Kumar, D., Kumar, N., Qayyum, A., Saeed, A., and Bhatti, S. M., 2014. Environmental concerns of underground coal gasification, Renewable and Sustainable Energy Reviews, 31, 600-610.

International Energy Agency, 2012. Energy technology perspectives 2012: pathways to a clean energy system.

International Society for Rock Mechanics (ISRM), Commission on standardization of laboratory and field tests, 1978. Suggested methods for the quantitative description of discontinuities in rock masses. Int. J. Rock Mech. Min. Sci. \& Geomech. Abstr 15(6), 319-368.

Ishida, H., Kobayashi, S., Kana, S., Hasegawa, T., Fujimori, S., Shin, Y., Takahashi, K., Masui, T., Tanaka, A., and Honda, Y., 2014, Global-scale projection and its sensitivity analysis of the health burden attributable to childhood undernutrition under the latest scenario framework for climate change research, Environ. Res. Lett. 9 (6) 064014e064022

Itasca, 2014. User's Manual, FLAC 7.0. Itasca Consulting Group Inc., Minneapolis, Minnesota (USA).

Johnston, D.H., 1987. Physical properties of shale at temperature and pressure, Geophysics, 52, 1391-1401.

Kim, C. J., and Sohn, C.H., 2012. A novel method to suppress spontaneous ignition of coal stockpiles in a coal storage yard. Fuel Process Technology, 100, 73-83.

Klimenko, A.Y., 2009. Early ideas in underground coal gasification and their evolution. Energies, Vol. 2, S. 456-476.

Lamas, B., and Cámara, A., 2014. Application of multicriteria algorithm to select suitable areas for storing CO2: CO2 SiteAssess software, Energy Procedia 63, 4977-4986.

Naghouni, A. F. 2013. CO2 Sequestration in UCG, PhD thesis, Calgary, Alberta.

Najafi, M., Mohammad, S., Jalali, E., and Khalo, K. R., 2014. Thermal-mechanical-numerical analysis of stress distribution in the vicinity of underground coal gasification (UCG) panels, International Journal of Coal Geology, 134-135, 1-16.

Rajwa S., Lubosik L., Wrana A., Masny W., Rodriguez A., Gorka T., Rüterkamp P., Peters S., Schlueter R., Farret,R., Laouafa, F., Syrek R., Galera M.J., Jimenez A., Pozo V., Rodrigo C., Kostur K., Durove J., Laciak M., Vavrek P., Durdan M., Kacur J., Bocan J., Stace R., Wanatowski D., Marshall A., Yang L.T., Ekneligoda T.C., 2017. Underground coal gasification in operating mines and areas of high vulnerability. European Commission Research Programme of the Research Fund for Coal and Steel (COGAR), Final Report.

Ranjith, P.G., Daniel, R., Bai, J. C., Samintha, M. and Perera, A., 2012. Transformation plasticity and the effect of temperature on the mechanical behaviour of Hawkesbury sandstone at atmospheric pressure. Engineering Geology, No. 151, $120-127$.

Rybacki, E., Reinicke, A., Meier, T., Makasi, M., and Dresen, G., 2015. What controls the mechanical properties of shale rock? Part 1: Strength and Young's modulus, Journal of Petroleum Science and Engineering, 135, 702-722.

Sarhosisa,V., Yang, D., Yong, Y., and Kempk, T., 2013. Coupled hydro-thermal analysis of underground coal gasification reactor cool down for subsequent CO2 storage, Energy Procedia, 40, 428 - 436.

Shirsat, A.V., 1989. Modelling of cavity growth in underground coal gasification, MSc Thesis, Master of Science, Texas Tech 
University.

Sun, Q., Lü, C., Liwen, C., Li W., Geng, J., and Zhang, W., 2016. Thermal properties of sandstone after treatment at high temperature, International Journal of Rock Mechanics \& Mining Sciences, 85, 60-66.

Tian, H., 2013. Development of a Thermo-Mechanical model for rocks exposed to high temperatures during underground coal gasification, PhD thesis RWTH Aachen University, Germany.

Xia, T., Zhou F., Liu, J., Kang, J., and Gao, F., 2014. A fully coupled hydro-thermo-mechanical model for the spontaneous combustion of underground coal seams, Fuel, 125, 106-115.

Yang, D., Sarhosis, V., and Sheng, Y., 2014. Thermal-mechanical modelling around the cavities of underground coal gasification, Journal of the Energy Institute, 1-9.

Yang-Lintao, Marshall, A. M., Wanatowski, D., Stace, R., \& Ekneligoda, T., 2017. Effect of high temperatures on sandstone - a computed tomography scan study, International Journal of Physical Modelling in Geotechnics, 17(2), 75-90. http://doi.org/10.1680/jphmg.15.00031.

Zao, X.G., Wang,J., Chen, F., Li, P.F., Ma, L.K., Xie, J.L., and Liu, Y.M., 2016, Experimental investigations on the thermal conductivity characteristics of Beishan granitic rocks for China's HLW disposal. Tectonophysics 683, 124-137.

Zhang, H., Liu. J., and Elsworth, D., 2008. How sorption-induced matrix deformation affects gas flow in coal seams: a new FE model. Int J Rock Mech Min; 45, 1226-36. 